Article

\title{
Enhanced Mechanical Properties in ED-Machinable Zirconia-Tungsten Carbide Composites with Yttria-Neodymia Co-Stabilized Zirconia Matrix
}

\author{
Andrea Gommeringer, Frank Kern * and Rainer Gadow \\ Institute for Manufacturing Technologies of Ceramic Components and Composites (IFKB), \\ University of Stuttgart, Allmandring 7b, D-70569 Stuttgart, Germany; \\ andrea.gommeringer@ifkb.uni-stuttgart.de (A.G.); rainer.gadow@ifkb.uni-stuttgart.de (R.G.) \\ * Correspondence: frank.kern@ifkb.uni-stuttgart.de; Tel.: +49-711-6856-8301
}

Received: 15 May 2018; Accepted: 30 May 2018; Published: 5 June 2018

\begin{abstract}
The electrical discharge machining-process (EDM) is a smart solution to optimize the manufacturing chain of customized and complex shaped ceramic components. To comply with the high requirements for the machine and mold design, it is necessary to improve the mechanical properties of ED-machinable ceramics. In this study, ceramic composites with a tetragonal zirconia matrix and tungsten carbide as electrically conductive dispersion were investigated. To improve the toughness of this high strength material, co-stabilized zirconia coated with yttria and neodymia as dopants were used in the compositions with 1.5/1.5 and 1.75/1.25 mol \%. These recipes were compared to commercial 3Y-TZP as a reference matrix material combined with the same WC raw powder. The electrically conductive phase content was varied from 20 to $28 \mathrm{vol} \%$. For all compositions, the ceramic blanks were hot pressed at identical dwell and pressure, but with various sintering temperatures $\left(1300{ }^{\circ} \mathrm{C}\right.$ to $\left.1450{ }^{\circ} \mathrm{C}\right)$ and then tested with respect to the mechanical and electrical properties. By variation of the stabilizer system, a significantly higher toughness of up to 11.3 MPa $\sqrt{ } \mathrm{m}$ compared to $5.3 \mathrm{MPa} \sqrt{ } \mathrm{m}$ for 3Y-TZP-20WC is achieved while the bending strength stays at a comparable high level of $>1500 \mathrm{MPa}$.
\end{abstract}

Keywords: co-stabilized zirconia; TZP-WC; mechanical properties; EDM

\section{Introduction}

Zirconia-based ceramics show a unique combination of strength and fracture resistance, which qualifies them for various structural applications at ambient temperature. The reason for these excellent mechanical properties is transformation toughening, a stress-induced martensitic transformation of metastable tetragonal to stable monoclinic phase [1,2]. This transformation comes along with volume expansion and shear and the transformation zone in the wake of a running crack acts to reduce stress intensity at the crack tip and prevent or retard crack growth. Applications operating under a high mechanical load in biomedical and mechanical engineering can be addressed [3,4]. As the phase transitions are thermally reversible, retaining the tetragonal high-temperature phase at room temperature requires the addition of stabilizing alio- or isovalent cations [5-7]. Therefore, tetragonal zirconia polycrystals (TZP - the fine grain variety of partially stabilized zirconia) are typically stabilized by either Yttria $\left(\mathrm{Y}_{2} \mathrm{O}_{3}\right)$ or Ceria $\left(\mathrm{CeO}_{2}\right)$ [1]. The former favors high strength and moderate toughness while the latter acts vice versa [8]. It has been shown in several publications that by a combination of small and large trivalent dopants such as yttria and neodymia or ytterbia and neodymia, TZP materials combining high strength and toughness can be produced [9-12].

The typical compositions quoted in literature are 1Y2Nd-TZP and 1.5Y1.5Nd-TZP (number refer to $\mathrm{mol} \%$ rare earth oxide $\mathrm{RE}_{2} \mathrm{O}_{3}$ ). These powders are not commercially available and are typically 
produced by a coating process from unstabilized zirconia powders and salts of rare earth compounds or by high energy milling of zirconia and stabilizer oxides [13,14]. As the tetragonal stability field in the system $\mathrm{Nd}_{2} \mathrm{O}_{3}-\mathrm{ZrO}_{2}$ is much narrower than in the system $\mathrm{Y}_{2} \mathrm{O}_{3}-\mathrm{ZrO}_{2}$, the TZP forms a characteristic bimodal microstructure with small tetragonal grains enriched in yttria and a large grain cubic phase enriched in neodymia $[12,15,16]$. Despite the small grain size, the tetragonal phase in these materials is extremely transformable resulting in high toughness. Properly processed, these co-stabilized materials retain a stabilizer gradient structure. Overfiring, however, results in a sudden breakdown of mechanical properties and the formation of monoclinic zirconia [11,12].

It has also been shown that such TZP are attractive matrix materials for ceramic composites. In alumina toughened zirconia materials, it was shown that in ATZ with the Y,Nd-TZP matrix much higher, the toughness can be preserved than in comparable Y-TZP with an identical alumina content $[8,17,18]$. Ultimate strength values of $2 \mathrm{GPa}$ such as in $3 \mathrm{Y}-\mathrm{TZP} / 20$ mass $\%$ alumina are, however, not possible. This is the result of inverted strength toughness correlations as reported by Swain $[8,17]$.

Y-TZP-WC composites with compositions suitable for ED-machining were developed by Pedzych [18]. As such, the materials are electrically conductive if a sufficient amount of WC is added. These composites soon came into the focus of groups elaborating electrically discharge machinable ceramics. The first attempts to improve fracture resistance in TZP-WC materials were reported by Jiang by reducing the stabilizer content of the Y-TZP matrix [19]. The same research group published the first materials consolidated by SPS [20]. Later, Y,Nd-TZP based composites with a high amount of tungsten carbide were introduced [21]. These materials show rather unique combinations of extremely high 3-point bending strength of $2 \mathrm{GPa}$ and indentation fracture resistance values of $10 \mathrm{MPa} \sqrt{ } \mathrm{m}$.

In electrical discharge machining (EDM), sparks between two electrodes-a working electrode which is either a negative form of the cavity to be produced (die-sinking) or a wire and an electrically conductive workpiece-can be exploited to remove material from the workpiece [22,23]. The process was developed in the 1940s by Lazarenko and is today frequently applied as a precision machining technology for metals [22]. The fact that the process, unlike conventional machining processes such as milling or grinding, is mechanically stress-free makes it very attractive for the machining of materials of high hardness which are conventionally difficult to machine. EDM has become a standard process for the machining of cemented carbides (for example, WC-Co) [24]. The first attempts to machine ceramics date back to the 1970s, the ceramics applied were intrinsically conductive materials such as boron carbide, titanium diboride, and $\mathrm{SiSiC} \mathrm{[25].} \mathrm{As} \mathrm{these} \mathrm{materials} \mathrm{are} \mathrm{typically} \mathrm{not} \mathrm{applicable}$ or too expensive for many load-bearing applications, new ED-machinable materials were developed which are based on strong and tough structural ceramic matrices such as silicon nitride and 3Y-TZP and a conductive dispersion of a transition metal carbide, nitride, or boride. $\mathrm{Si}_{3} \mathrm{~N}_{4}$-TiN, Y-TZP-TiN, and Y-TZP-NbC are commercially available. They have, however, remained niche-products for special applications. Recently, materials with an alumina-zirconia matrix and titanium or niobium carbide dispersions were reported [26,27].

Y-TZP-WC composite ceramics with an identical basic composition (20-28 vol \% WC) as in this study, but based on a standard 3Y-TZP (Tosoh 3Y-SE) hot pressed at $1450{ }^{\circ} \mathrm{C}$ for $2 \mathrm{~h}$ at $60 \mathrm{MPa}$ pressure were previously investigated in detail with respect to ED-machinability, microstructure, and mechanical properties. Besides a moderate toughness of 5.3-5.5 $\pm 0.2 \mathrm{MPa} \sqrt{ } \mathrm{m}$ varying very little with the fraction of WC used, the strength varied from 1228-1595 MPa with a maximum of $24 \mathrm{vol} \%$ WC. Hardness increased linearly from $1567 \mathrm{HV} 10$ for $20 \mathrm{vol} \%$ WC to $1650 \mathrm{HV} 10$ for $28 \mathrm{vol} \%$ WC. Electrical conductivity increased from $17 \mathrm{kS} / \mathrm{m}$ to $72 \mathrm{kS} / \mathrm{m}$ in the same range [28]. More demanding applications in complex structural components with a filigree structure, however, demand materials with higher damage tolerance. In this study, this topic is addressed to obtain a set of data that can be directly compared to the current state-of-the-art. 


\section{Materials and Methods}

The starting powders for the hot pressed ceramic blanks were Tungsten Carbide WC DN4.0 (H.C. Starck, Germany, $\mathrm{S}_{\mathrm{BET}}=4 \mathrm{~m}^{2} / \mathrm{g}$, agglomerate size $\mathrm{d}_{50}=300 \mathrm{~nm}$, crystallite size $100 \mathrm{~nm}$ ) and unstabilized monoclinic zirconia TZ-0 (Tosoh, Japan, $\mathrm{S}_{\mathrm{BET}}=17 \mathrm{~m}^{2} / \mathrm{g}$, agglomerated, crystallite size 40 $\mathrm{nm}$ ) which is the basis for the coating process via the suspension drying process described by Yuan [13]. Therefore, commensurate amounts of yttria and neodymia were dissolved in boiling $5 \mathrm{~N}$ nitric acid. The solution was then added to zirconia dispersed in isopropanol and doped with a small amount of alumina (0.5 vol \%). The mixture was then gently ball milled with 3Y-TZP milling balls (5 mm diameter) over $24 \mathrm{~h}$. After separating the milling balls, the solvent was evaporated. Then the product was pre-calcined up to $350{ }^{\circ} \mathrm{C}$, ground with a mortar and pestle and sieved before calcining again at $600{ }^{\circ} \mathrm{C}$ in air. According to this procedure, two different batches of zirconia were prepared: the first one with $1.5 \mathrm{~mol} \%$ yttria and $1.5 \mathrm{~mol} \%$ neodymia (labeled 1.5Y-1.5Nd-TZP) and a second with $1.75 \mathrm{~mol} \%$ yttria and $1.25 \mathrm{~mol} \%$ neodymia (1.75Y-1.25Nd-TZP). These co-stabilized zirconia powders were the basis for manufacturing three compound batches with 20, 24, and $28 \mathrm{vol} \%$ tungsten carbide for each TZP. The compounds were attrition milled in isopropanol with TZP milling balls ( 2 mm diameter) over $2 \mathrm{~h}$. The dried compounds were sieved through a 100- $\mu \mathrm{m}$-mesh to receive an additive-free hot pressing powder. For each composition, two cylindrical ceramic blanks of $40 \mathrm{~mm}$ diameter and $\sim 2.5 \mathrm{~mm}$ thickness were hot pressed (FCT Anlagenbau, Sonneberg, Germany) at different sintering temperatures $\left(1300 / 1325 / 1350 / 1375 / 1400 / 1425 / 1450{ }^{\circ} \mathrm{C}\right)$. Samples sintered at $>1400^{\circ} \mathrm{C}$ decomposed to a formation of monoclinic zirconia or even fractured after sintering and were not further characterized. The heating schedule was from room temperature to $1050{ }^{\circ} \mathrm{C}$ at $24 \mathrm{~kW}$ electrical power $(\sim 50 \mathrm{~K} / \mathrm{min})$, at an axial pressure of $2.5 \mathrm{MPa}$. Then the temperature was increased at $10 \mathrm{~K} / \mathrm{min}$ to $1150{ }^{\circ} \mathrm{C}$ and, simultaneously, the load was increased to $25 \mathrm{MPa}$. Heating from $1150^{\circ} \mathrm{C}$ to the final temperature was carried out in $10 \mathrm{~min}$. Simultaneously, the pressure was increased to $60 \mathrm{MPa}$ (resulting at a variable heating rate of $15-30 \mathrm{~K} / \mathrm{min}$ ). Pressure and dwell remained constant at $60 \mathrm{MPa}$ and $2 \mathrm{~h}$. the initial cooling rate between the final temperature was $30 \mathrm{~K} / \mathrm{min}$ with the heater switched off. The hot pressed samples were ground and polished until the surface was mirror-like. The density was measured by Archimedes' principle (buoyancy measurement in water performed by using entire polished disks measuring the weight in air and immersed in water-accuracy of temperature measurement $0.1 \mathrm{~K}$ ). The Young's modulus was calculated by the resonance frequency method (IMCE, Genk, Belgium). The hardness was quantified by Vickers hardness HV10 (Bareiss, Germany). The electrical conductivity was measured by a four-point setup which detects the electrical resistance. To characterize the mechanical properties, ceramic bars were tested by a 4-point bending test (10 samples) and the indentation strength in bending ISB (4 samples each) (Zwick, Ulm, Germany). For more information about the phase composition and its change while disruption, the polished surfaces and fractured faces were analyzed by X-ray diffraction (X'Pert MPD, PANalytical, Kassel, Germany, $\mathrm{Cu} \mathrm{K}_{\alpha 1}$ ). The phase content of the monoclinic and tetragonal zirconia was then calculated on the base of the peak fitting of the monoclinic (111) and the tetragonal (101) reflex with the help of the calculation curve of Toraya [29]. Scanning electron microscope images (Gemini, Zeiss, Oberkochen, Germany, in lens, SE mode) were taken from the polished and thermally etched surfaces to investigate the microstructure and detect the grain size of zirconia grains; the grain sizes were determined by the linear intercept method with a multiplication factor of 1.57. For the thermal etching procedure, the polished samples were heated in a molybdenum furnace (Xerion, Germany) in a hydrogen atmosphere to $1150{ }^{\circ} \mathrm{C}$ at a $5 \mathrm{~K} / \mathrm{min}$ heating rate; the dwell was $1 \mathrm{~min}$.

\section{Results}

\subsection{Density, Electrical Conductivity, and Mechanical Properties}

The density, Vickers hardness, and Young's modulus of 1.5Y-1.5Nd-TZP-WC (a) and 1.75Y-1.25Nd-TZP-WC (b) with 20, 24, and $28 \mathrm{vol} \% \mathrm{WC}$ depending on the sintering temperature 
are shown in Figure 1. The materials are almost fully dense ( $>99.5 \%$ of theoretical) at all sintering temperatures. Materials containing higher fractions of WC tend to show slightly lower relative densities across the whole sintering temperature range. The hardness increases very slightly with increasing sintering temperature. This is probably due to the also very slight increase in the relative density. The hardness increase with increasing WC content can be expected due to the higher hardness of WC compared to zirconia. The change of stabilizer has a minor effect. In 1.5Y-1.5Nd-TZP-WC, the hardness difference between materials of different tungsten carbide contents is larger while for 1.75Y-1.25Nd-TZP-WC, the hardness values are closer together. The Young's modulus data show a much higher scattering of individual values than the hardness data (the main factor here is the measurement of the sample thickness; an accuracy of $1 \mu \mathrm{m}$ causes an error of $1 \mathrm{GPa}$ for a disk of $2 \mathrm{~mm}$ thickness). The global trends are evident. Increasing the WC content leads to an increase of Young's modulus. TZP richer in yttria have a slightly higher Young's modulus.

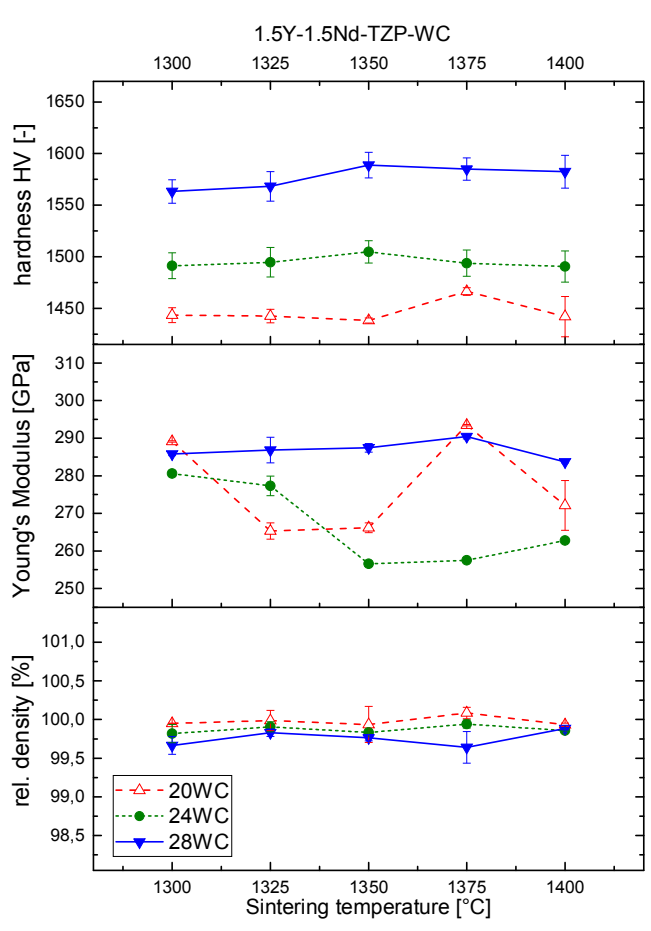

(a)

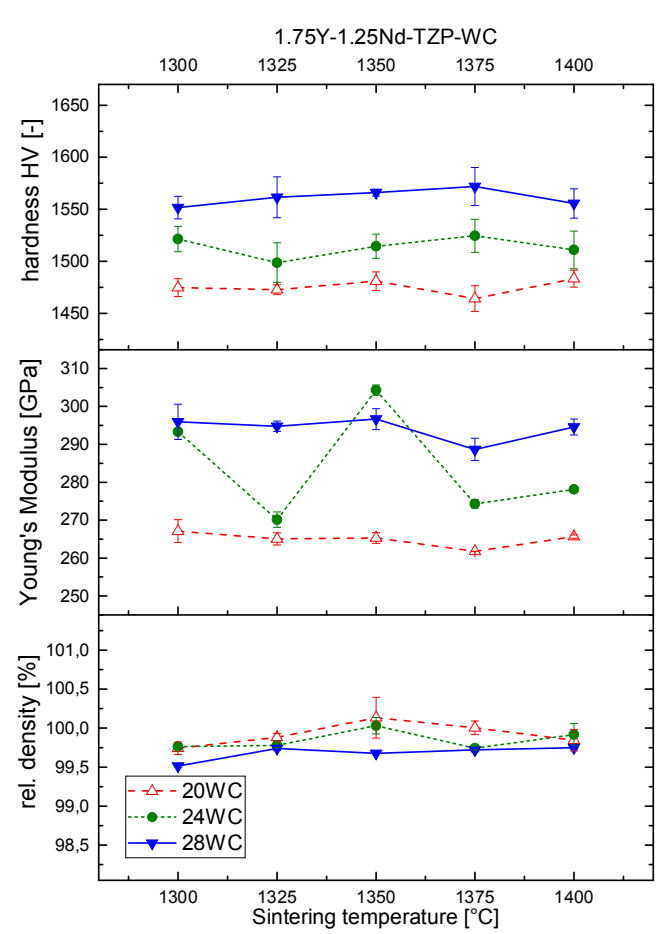

(b)

Figure 1. The results for the relative density, Young's Modulus, and Vickers hardness: (a) 1.5Y-1.5NdTZP-WC; (b) 1.75Y-1.25Nd-TZP-WC.

Figure 2 shows the electrical conductivity, bending strength, and fracture toughness of 1.5Y-1.5Nd-TZP-WC (a) and 1.75Y-1.25Nd-TZP-WC (b) with 20, 24, and 28 vol \% WC depending on sintering temperature. Concerning the electrical conductivity, identical trends are observed for both stabilizer recipes. It is evident that increasing the fraction of the electrically conductive WC phase improves the conductivity significantly. The electrical conductivity shows a constant level depending only on the composition and is invariant with the sintering temperature. Moreover, it is obvious that the compositions selected are close to the percolation threshold as the conductivities rise drastically from $3-4 \mathrm{kS} / \mathrm{m}$ for $20 \mathrm{vol} \%$ WC over $18-23 \mathrm{kS} / \mathrm{m}$ for $24 \mathrm{vol} \%$ WC to $40-43 \mathrm{kS} / \mathrm{m}$ for $28 \mathrm{vol} \% \mathrm{WC}$. The electrical conductivities are far above the minimum value of required electrical conductivity of $1 \mathrm{~S} / \mathrm{m}$ for ED-machinability as defined by Panten [30]. The measured level of 4-point bending strength is attractive. The strength of 1.5Y-1.5Nd-TZP-20-24WC ranges from 1100-1400 MPa. $1.5 \mathrm{Y}-1.5 \mathrm{Nd}-\mathrm{TZP}$ with $20-24 \mathrm{vol} \% \mathrm{WC}$ have identical strength with a intermedium maximum at $1350^{\circ} \mathrm{C}$. Material with $28 \mathrm{vol} \% \mathrm{WC}$ is slightly stronger and shows a maximum strength of $1410 \mathrm{MPa}$ at $1325^{\circ} \mathrm{C}$. 
In 1.75Y-1.25Nd-TZP-WC, the average strength is $~ 150 \mathrm{MPa}$ higher than in 1.5Y-1.5Nd-TZP-WC. Here the strength increases with WC content and slightly decreases with increasing sintering temperature. The maximum of $1535 \mathrm{MPa}$ is achieved with $1.75 \mathrm{Y}-1.25 \mathrm{Nd}$-TZP-28WC sintered at $1350{ }^{\circ} \mathrm{C}$. Toughness values measured by a ISB-test show the contrary tendency. In general, materials with higher neodymia stabilizer content and lower tungsten carbide content show significantly higher toughness. For 1.5Y-1.5Nd-TZP-WC, the highest toughness values of $10.1-11.3 \mathrm{MPa} \sqrt{ } \mathrm{m}$ were observed for $20 \mathrm{vol} \% \mathrm{WC}$ followed by materials with $9.5-10 \mathrm{MPa} \sqrt{ } \mathrm{m}$ at $24 \mathrm{vol} \% \mathrm{WC}$. For $1.5 \mathrm{Y}-1.5 \mathrm{Nd}-\mathrm{TZP}-28 \mathrm{WC}$, the toughness is almost constant at $9 \mathrm{MPa} \sqrt{ } \mathrm{m}$. The influence of sintering temperature is not very pronounced. 1.75Y-1.25Nd-TZP-WC shows a maximum toughness of $9-10 \mathrm{MPa} \sqrt{ } \mathrm{m}$ at the lowest WC content. Materials with $24-28 \mathrm{vol} \%$ show a constant toughness of $8.5 \mathrm{MPa} \sqrt{ } \mathrm{m}$, which is still very promising especially considering the high strength.

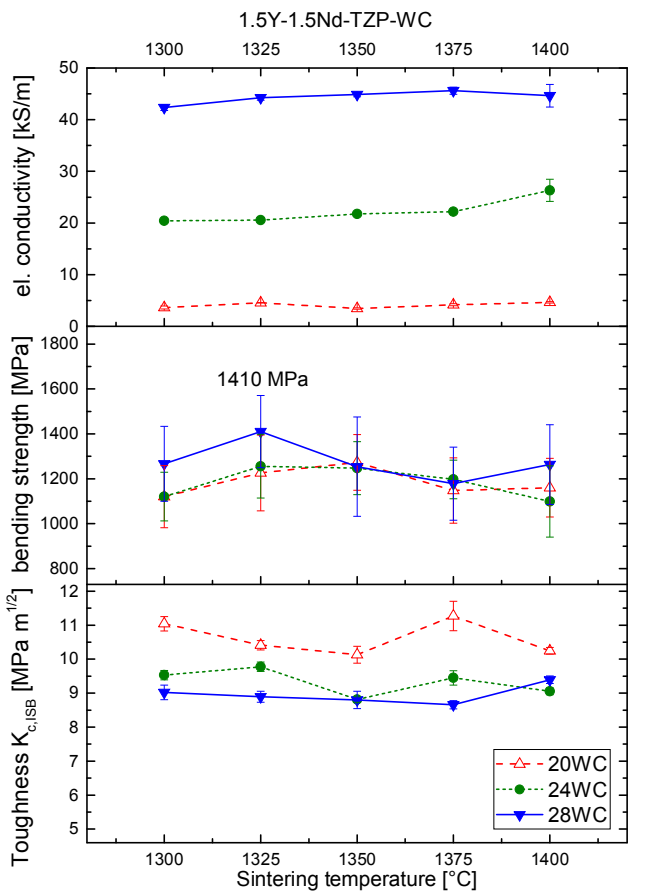

(a)

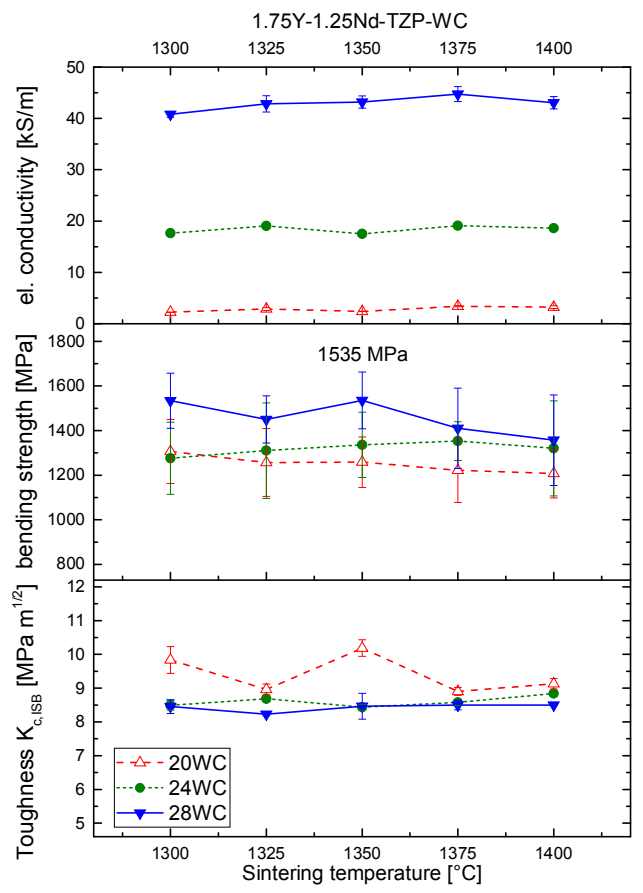

(b)

Figure 2. The results for electrical conductivity, 4-point bending strength, and fracture toughness: (a) 1.5Y-1.5Nd-TZP-WC; (b) 1.75Y-1.25Nd-TZP-WC.

\subsection{Phase Analysis}

The phase analysis was more difficult to perform due to the coincidence of the monoclinic (111)-peak of zirconia with the (001) peak of tungsten carbide. Therefore, for phase analysis in TZP-WC, it is assumed that the (111) and (111) peaks appear in the same fixed ratio of 100/68 as in untextured monoclinic zirconia (JCPDS 07-0343) [31].

The monoclinic phase content in polished and fractured surfaces of 1.5Y-1.5Nd-TZP-WC and 1.75Y-1.25Nd-TZP-WC is shown in Figure 3. In 1.5Y-1.5Nd-TZP-WC, polished surfaces-representing the bulk of the material-already contain measurable amounts of monoclinic phase. The monoclinic content slightly increases with sintering temperature from $3-5 \mathrm{vol} \%$ at $1300{ }^{\circ} \mathrm{C}$ to $5-8 \mathrm{vol} \%$ at $1400{ }^{\circ} \mathrm{C}$. This material already contains a $>40 \%$ monoclinic phase in the as-fired state. The monoclinic content in the fracture faces rises between $1300-1350{ }^{\circ} \mathrm{C}$ and then stays at a constant level of $\sim 70 \%$ for the individual WC contents. The difference between fractured and polished samples which represents the stress-induced transformability of zirconia is very high compared to co-precipitated material [28]. In 1.75Y-1.25Nd-TZP-WC materials, the polished samples always contain much less monoclinic phase 
$(0-3 \mathrm{vol} \%)$. Moreover, the monoclinic phase content in the fracture faces is almost identical with the transformability. The transformability is comparable to 1.5Y-1.5Nd-TZP-WC. The grain sizes measured by line intercept method (Figure 3) change with sintering temperature. While grains are extremely fine (130-150 nm) at a sintering temperature of $1300{ }^{\circ} \mathrm{C}$, the materials become much coarser (170-280 nm) at $1400{ }^{\circ} \mathrm{C}$. Samples sintered at a low temperature show no significant correlation of grain size and WC carbide content; at a high sintering temperature, the grain refining effect of the tungsten carbide becomes more pronounced as samples with higher WC content stay more fine-grained.

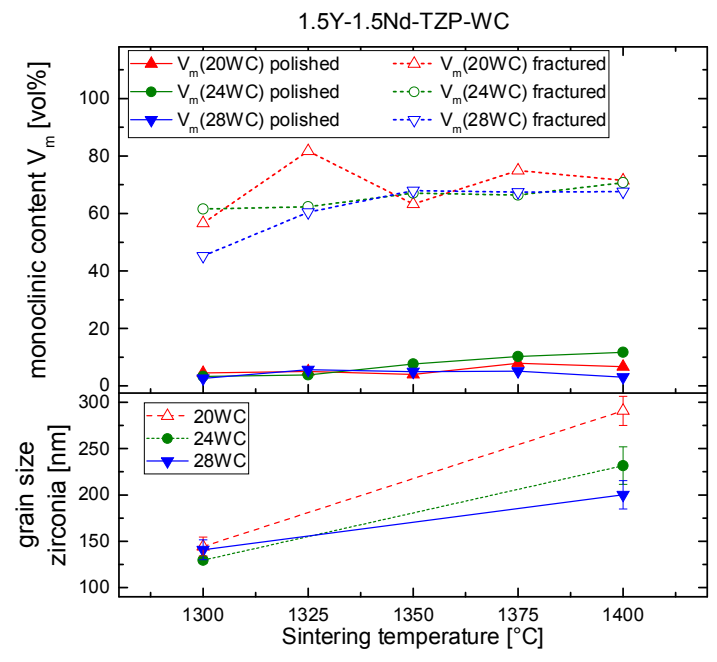

(a)

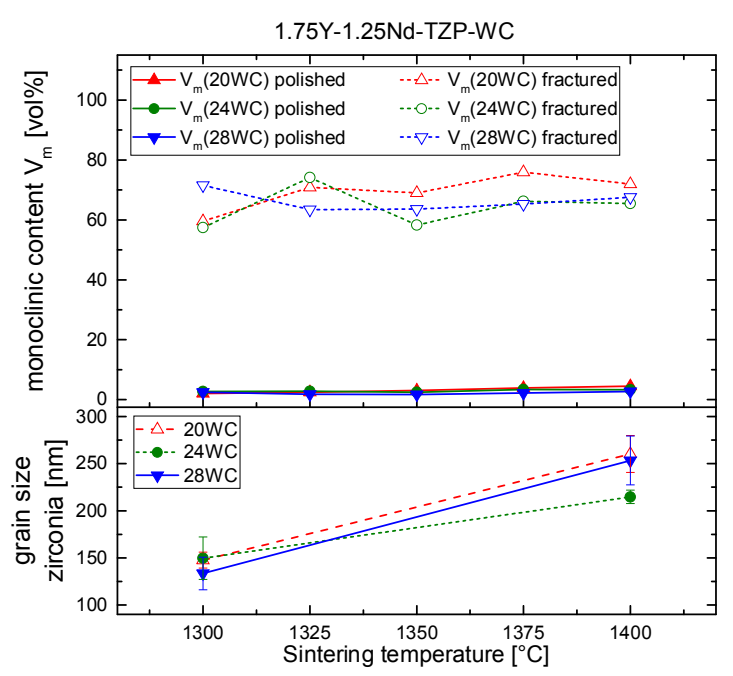

(b)

Figure 3. Zirconia monoclinic phase content in polished and fractured surfaces and grain size of the zirconia matrix: (a) 1.5Y-1.5Nd-TZP-WC; (b) 1.75Y-1.25Nd-TZP-WC.

Besides the monoclinic phase, the content of the cubic phase also has to be considered. However, due to another coincidence of the tetragonal (004), (400), and cubic (400) peaks of zirconia with the (111) peak of WC in the $70-75^{\circ} 2 \theta$-range the cubic phase cannot be determined as usual by integrating these peaks of zirconia [32]. The patterns of polished and fractured materials (Figure 4) show that a considerable amount of cubic phase is contained. The cubic content in polished samples is detectable as a shoulder in the tetragonal (101) peak. This shoulder is more pronounced at higher sintering temperatures. In the fracture surfaces, most of the tetragonal phase is transformed. Thus, for fracture surfaces, the cubic and tetragonal peaks can be separated. Especially for a high sintering temperature, a more cubic than tetragonal phase was observed. The cubic content in the fractured surfaces can be estimated at 10-15 vol \%. Qualitatively—and in good accord with thermodynamics [15]—there seems to be slightly more cubic phase at higher sintering temperatures. For 1.75Y-1.25Nd-TZP-WC, the tendencies are similar and the material contains slightly less cubic. The peak shift between polished and fractured surfaces is a consequence of compressive residual stress introduced by $\mathrm{t}-\mathrm{m}$ phase transformation during fracture. A rough estimation of the transformation toughness increment according to McMeeking and Evans [33] using measured values for Young's modulus, phase composition, and considering the compositional influence and higher X-Ray attenuation of WC leads to a transformation toughness level of $\mathrm{K}_{\mathrm{IC}}{ }^{\mathrm{T}} \sim 3 \mathrm{MPa} \sqrt{ } \mathrm{m}$ for the least and $<5 \mathrm{MPa} \sqrt{ } \mathrm{m}$ for the most transformable materials. 


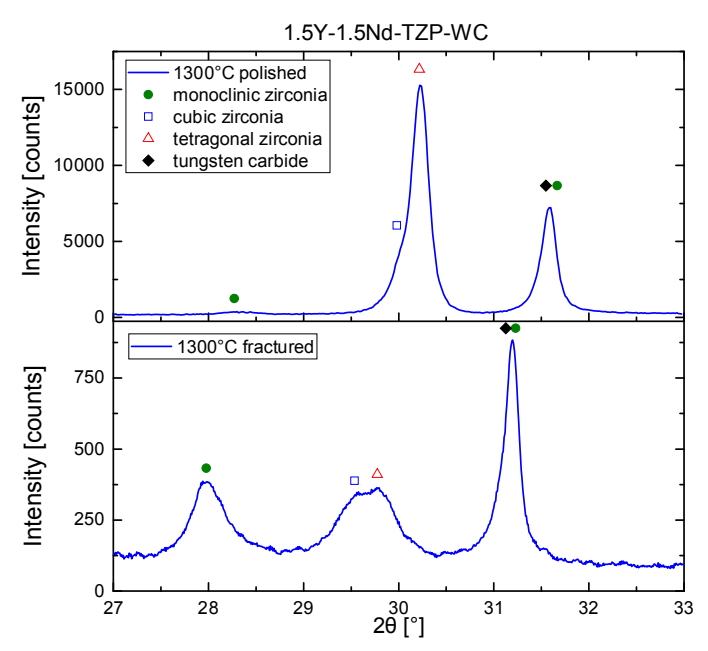

(a)

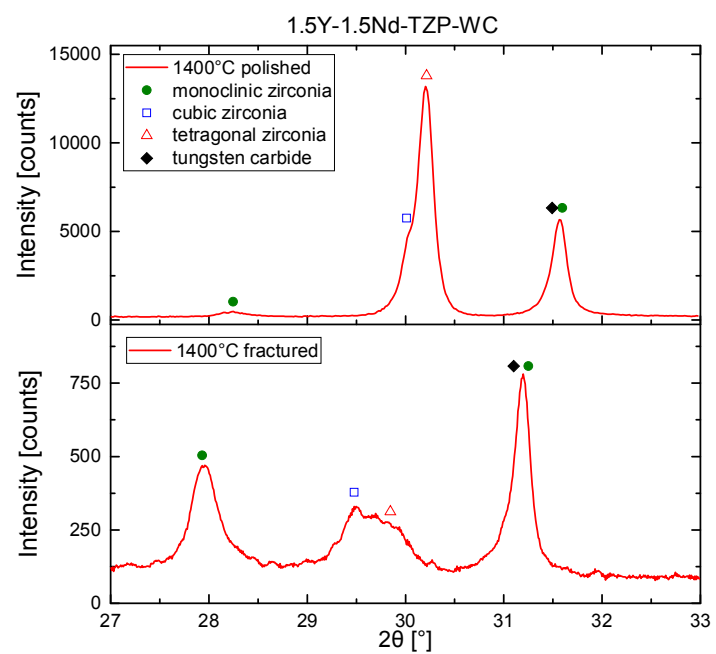

(b)

Figure 4. The X-Ray traces of $1.5 \mathrm{Y}-1.5 \mathrm{Nd}$-TZP-20WC sintered at 1300 and $1400{ }^{\circ} \mathrm{C}$, comparing the fingerprint range between $27-33^{\circ} 2 \theta$ of polished and fracture surfaces.

\subsection{Microstructure}

The microstructure of four typical compositions (low and high WC content, low and high sintering temperature) and the crack propagation herein is compared in Figure 5. Grain boundaries were revealed by thermal etching. Some microstructure details are indicated in the SEM images to make the following statements more clear. The ceramics show a characteristic assembly of three phases. Small dark grains with a corrugated surface are tetragonal zirconia, large dark grey grains with a smooth surface are cubic zirconia, and light grey grains with a faceted shape, which are strongly attached by hydrogen atmosphere are tungsten carbide. As expected, the variations in sintering temperature lead to grain growth of the TZP matrix, the tungsten carbide apparently does not grow. An increasing fraction of tungsten carbide dispersion leads to grain refinement of the 1.5Y-1.5Nd-TZP matrix. Replacing yttria by neodymia even at this small increment of only $0.25 \mathrm{~mol} \%$ leads to a visible increase of cubic zirconia grains. Cubic grains grow faster than the tetragonal grains. The examination of crack propagation originating from a HV10 Vickers indent placed after etching shows two clear tendencies. The materials show a mixed fracture mode. Intergranular fracture around WC grains and very frequent transgranular fracture through TZP grains. This correlates well to the observation of Jiang [19]. Crack branching and crack bridging effects which enhance fracture toughness can be clearly identified. Cracks are frequently stopped within TZP grains and re-initiated in the close vicinity. Another interesting detail is the nano-roughness of fracture faces in tetragonal zirconia grains while cubic grains exhibit plain fractures Figure 5. SEM images of polished and thermally etched surfaces of 1.5Y-1.5Nd-TZP-WC and 1.75Y-1.25Nd-TZP-WC sintered at $1300{ }^{\circ} \mathrm{C}$ and $1400{ }^{\circ} \mathrm{C}$. Microstructure details remarked with arrows and comments. 

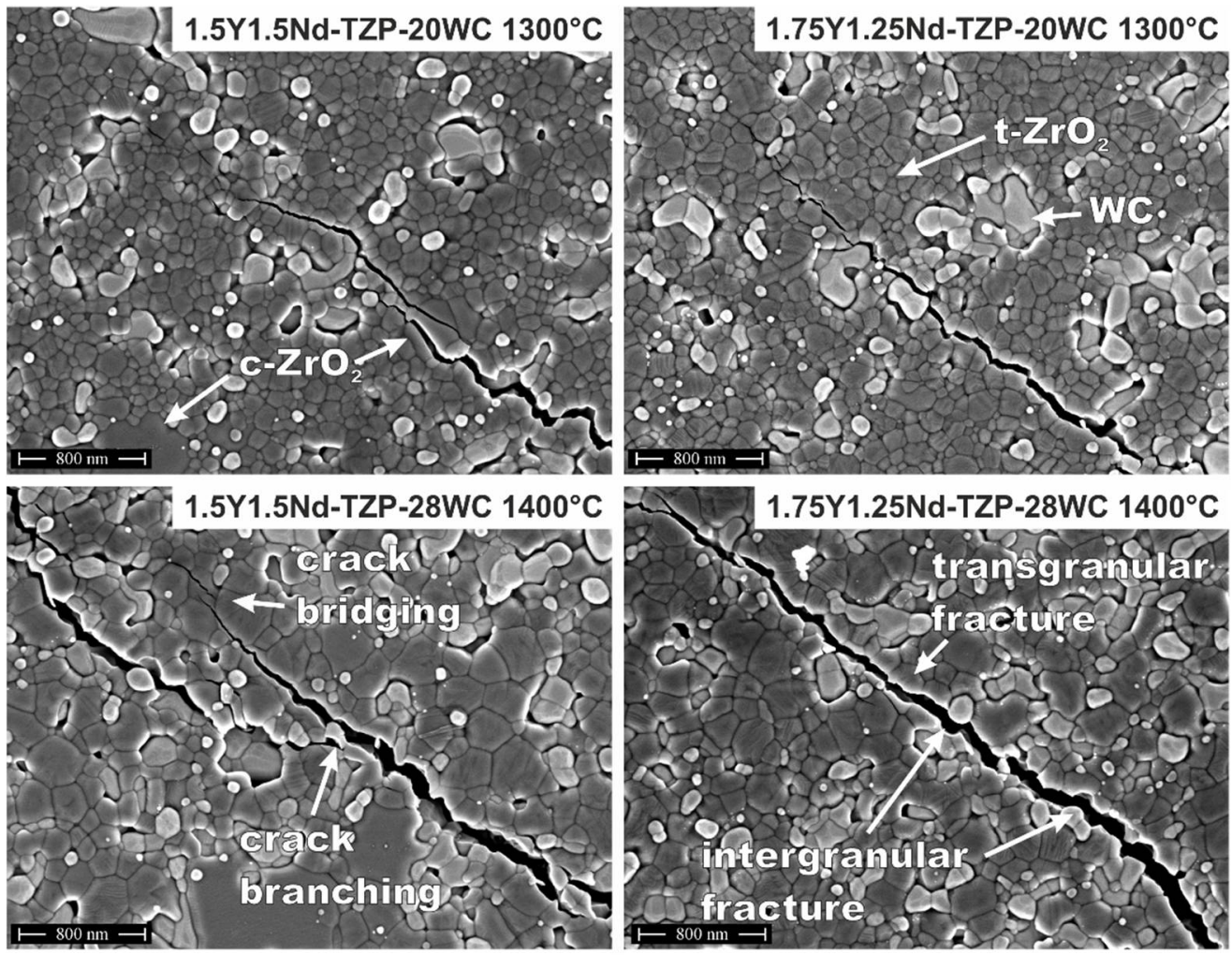

Figure 5. The SEM images of polished and thermally etched surfaces of 1.5Y-1.5Nd-TZP-WC and 1.75Y-1.25Nd-TZP-WC sintered at $1300{ }^{\circ} \mathrm{C}$ and $1400{ }^{\circ} \mathrm{C}$. Microstructure details remarked with arrows and comments.

\section{Discussion}

In order to understand the characteristics of the TZP-WC materials investigated, the compiled results have to be analyzed considering the interrelation of the microstructure, the phase composition, as well as the mechanical and electrical properties. Electrical conductivity can be interpreted in terms of percolation theory as the amount of electrically conductive phase, its grain size and distribution and the grain size of the insulating matrix are known. Theoretically, $16 \mathrm{vol} \%$ of conductive phase would be necessary to form a percolating conductive network of isometric homogeneously distributed particles [34]. In the present case, tungsten carbide nanoparticles tend to form aggregates that are non-isometric in shape. Therefore, the required fraction of WC is slightly higher. The lowest concentration of $20 \mathrm{vol} \% \mathrm{WC}$ is, however, close to the conductivity threshold so that small increments of WC addition lead to an exponential increase in conductivity. The distribution of these WC aggregates does not change with sintering temperature. Therefore, slight changes in conductivity observed can only be traced back to a coarsening of the TZP matrix and an increase of relative density. Compared to the standard 3Y-TZP-WC materials with significantly larger TZP grains $(370-430 \mathrm{~nm})$, the matrix grain size effect on conductivity is striking, as the latter show electrical conductivities higher by a factor of $2-5$ [28].

The Young's modulus and Vickers hardness show the expected increase with increasing WC content due to the higher hardness and Young's modulus of WC compared to TZP. The observed trends of fracture resistance and strength need to be explained considering the strength-toughness correlations in zirconia materials as outlined by Swain and Rose [8]. In the regime of low fracture resistance and at a given defect size, zirconia-based ceramics (TZP and TZP-alumina) show a positive correlation between strength and toughness [8]. In Y-TZP, this defect size limited correlation is valid up to a toughness of $\sim 7-8 \mathrm{MPa} \sqrt{ } \mathrm{m}$, corresponding to a contribution of $\sim 3-4 \mathrm{MPa} \sqrt{ } \mathrm{m}$ by toughening effects [35]. Above that value of toughness, a narrow transition range may occur. Then the strength-toughness correlations 
are inverted [8]. Increasing toughness leads to a decrease in strength. The materials studied are close to or even above the transition zone from defect size to transformation dominated behavior (R-curve domination) as the estimated transformation toughness values are in the range between 3-5 MPa $\sqrt{ } \mathrm{m}$. In the high toughness regime, the transformation of the tetragonal phase limits the strength, that is, a stress-induced phase transformation from tetragonal to monoclinic occurs before a defect is propagated. This effect is responsible for the reversal of strength-toughness correlations when shifting from a 1.5Y-1.5Nd-TZP to a 1.75Y-1.25Nd-TZP matrix. Previous studies on Y-Nd-TZP-alumina ceramics have shown identical tendencies $[11,36,37]$.

The reason for higher toughness in the neodymium richer systems is found in the phase relations and the size of the aliovalent stabilizer cations. The neodymia-zirconia system has considerably narrower tetragonal stability field ending at $\sim 0.8 \mathrm{~mol} \% \mathrm{Nd}_{2} \mathrm{O}_{3}$ and an extremely broad $\mathrm{t}+\mathrm{c}$ field while the yttria-zirconia system has a wider tetragonal field reaching to $2.5 \mathrm{~mol} \% \mathrm{Y}_{2} \mathrm{O}_{3}$ and a narrower $\mathrm{t}+\mathrm{c}$ field $[15,16]$. Consequently, the tetragonal phase in neodymia-richer TZP contains less stabilizer and is thus more transformable than the tetragonal phase in the yttria-richer TZP (see Figure 3). Due to the asymmetric distribution of the two cations in the tetragonal and cubic phases, more neodymia also means a higher content of the cubic phase. This effect can be clearly identified by the formation of a more pronounced shoulder in the (101)t and (111)c peaks and by observation of the microstructure. The effect of WC needs to be interpreted in terms of elastic constraint and the basic theory of transformation toughening as reported by McMeeking and Evans [33]. The higher the WC content, the higher the Young's modulus and the elastic constraint on the tetragonal grains. Stress-induced phase transformation is more facile if the surrounding matrix does not restrict the transformation related volume expansion. Thus, higher WC contents lead to lower transformability, a smaller size of the transformation zone and, thereby, to a lower transformation toughness increment. Moreover, in composites containing more WC, the corresponding zirconia content is lower. A part of the missing toughness increment is however equilibrated as the transformation toughness increment linearly rises with the Young's modulus of the material [33].

As TZP and WC have completely different elastic and thermophysical properties, the interpretation of fracture behavior has to include an at least qualitative analysis of residual cooling stress. The WC dispersion has a higher Young's modulus and lower CTE than the zirconia matrix. At the maximum sintering temperature, the composite can be considered stress free and will develop residual stresses during cooling. The onset for the build-up of residual stress is the temperature where the microstructure is frozen, that is, where relaxation effects can no longer be observed. WC grains will then be subject to hydrostatic compressive stress and TZP grains to hydrostatic tensile stress [38]. This CTE mismatch can be compensated by spontaneous transformation of tetragonal phase during cooling which, in fact, is observed for 1.5Y-1.5Nd-TZP-WC. As WC has high intrinsic strength and is moreover under compression (both axially and tangentially), it is not surprising that cracks always run around and not through WC grains. Tetragonal zirconia grains are subject to hydrostatic tensile stress (axial stress is compressive, tangentially stress is tensile). This state of residual stress favors transformation and transgranular fracture. A similar effect was observed upon addition of alumina (another dispersion with lower CTE and higher Young's modulus than zirconia) to 3Y-TZP by Kabir [39] and by Danilenko [40]. Cracks in tetragonal grains have shown deflection in the nanometer range at tetragonal domain boundaries [19].

\section{Conclusions}

Nanocomposites with a Y-Nd co-stabilized TZP matrix and a WC dispersion retain a nanoscale microstructure in the sintered state and provide a unique combination of high strength and high toughness. A sufficiently high electrical conductivity provides the basis for ED-machinability and potential application in complex load-bearing machine elements. Comparing the data obtained in the present study to previous studies done on standard 3Y-TZP-WC composites, it becomes evident that the main goal to improve the mechanical properties in terms of strength and fracture resistance by 
changing the stabilizer recipe in TZP was achieved. Fracture resistance can be almost doubled while keeping the strength comparable. The variation of the fraction and ratio of co-stabilizers can be applied to adjust the strength toughness-relations selectively depending on different technical requirements. Tougher materials provide more operational safety in applications where a single catastrophic event may occur while materials with lower fracture resistance are more favorable in applications under constant or alternating load. 1.5Y-1.5Nd-TZP-WC sintered at higher sintering temperature than $1400^{\circ} \mathrm{C}$ exhibited exaggerated formation of monoclinic and a further improvement of toughness seems hardly possible. The ultrafine grain size of the TZP matrix in the present study is favorable to achieve high mechanical strength. Refinement of the microstructure, however, also marks a potential drawback as the electrical conductivity is lower than in the 3Y-TZP-WC reference material. Implications on the ED-machinability will require a detailed investigation in a separate study.

Author Contributions: F.K. and A.G. designed the experiments, A.G. and F.K. manufactured the samples, A.G. performed all further experiments and analyzed the data. F.K. and A.G. wrote the paper. R.G. provided materials, technical and analytical equipment.

Acknowledgments: The authors kindly acknowledge the funding by DFG Deutsche Forschungsgemeinschaft under grant number KE 879 3-1, and would like to thank Moritz Kindelmann and Christopher Schweizer for their excellent legwork.

Conflicts of Interest: The authors declare no conflict of interest.

\section{References}

1. Hannink, R.H.J.; Kelly, P.M.; Muddle, B.C. Transformation Toughening in Zirconia-Containing Ceramics. J. Am. Ceram. Soc. 2000, 83, 461-487. [CrossRef]

2. Kelly, P.M.; Francis Rose, L.R. The martensitic transformation in ceramics-Its role in transformation toughening. Prog. Mater. Sci. 2002, 47, 463-557. [CrossRef]

3. Piconi, C.; Maccauro, G.; Muratori, F.; Brach del Prever, E. Alumina and zirconia ceramics in joint replacements. J. Appl. Biomater. Biomech. 2003, 1, 19-32. [PubMed]

4. Harrer, W.; Deluca, M.; Morrell, R. Failure analysis of a ceramic ball race bearing made of Y-TZP zirconia. Eng. Fail. Anal. 2014, 36, 262-268. [CrossRef]

5. Li, P.; Chen, I.-W.; Penner-Hahn, J.E. Effect of Dopants on Zirconia Stabilization-An X-ray Absorption Study: I, Trivalent Dopants. J. Am. Ceram. Soc. 1994, 77, 118-128. [CrossRef]

6. Li, P.; Chen, I.-W.; Penner-Hahn, J.E. Effect of Dopants on Zirconia Stabilization-An X-ray Absorption Study: II, Tetravalent Dopants. J. Am. Ceram. Soc. 1994, 77, 1281-1288. [CrossRef]

7. Li, P.; Chen, I.-W.; Penner-Hahn, J.E. Effect of Dopants on Zirconia Stabilization-An X-ray Absorption Study: III, Charge-Compensating Dopants. J. Am. Ceram. Soc. 1994, 77, 1289-1295. [CrossRef]

8. Swain, M.V.; Rose, L.R.F. Strength Limitations of Transformation-Toughened Zirconia Alloys. J. Am. Ceram. Soc. 1986, 69, 511-518. [CrossRef]

9. $\mathrm{Xu}$, T.; Vleugels, J.; van der Biest, O.; Wang, P. Mechanical properties of $\mathrm{Nd}_{2} \mathrm{O}_{3} / \mathrm{Y}_{2} \mathrm{O}_{3}$-coated zirconia ceramics. Mater. Sci. Eng. A 2004, 374, 239-243. [CrossRef]

10. Vleugels, J.; Xu, T.; Huang, S.; Kan, Y.; Wang, P.; Li, L.; van der Biest, O. Characterization of (Nd,Y)-TZP ceramics prepared by a colloidal suspension coating technique. J. Eur. Ceram. Soc. 2007, 27, 1339-1343. [CrossRef]

11. Kern, F. High toughness and strength in yttria-neodymia costabilized zirconia ceramics. Scr. Mater. 2012, 67, 301-304. [CrossRef]

12. Kern, F. Ytterbia-neodymia-costabilized TZP-Breaking the limits of strength-toughness correlations for zirconia? J. Eur. Ceram. Soc. 2013, 33, 965-973. [CrossRef]

13. Yuan, Z.X.; Vleugels, J.; van der Biest, O. Preparation of $\mathrm{Y}_{2} \mathrm{O}_{3}$-coated $\mathrm{ZrO}_{2}$ powder by suspension drying. J. Mater. Sci. Lett. 2000, 19, 359-361. [CrossRef]

14. Ohnishi, H.; Naka, H.; Sekino, T.; Niihara, K. Mechanical properties of $2.0-3.5 \mathrm{~mol} \% \mathrm{Y}_{2} \mathrm{O}_{3}$-stabilized zirconia polycrystals fabricated by the solid phase mixing and sintering method. J. Ceram. Soc. Jpn. 2008, 116, 1270-1277. [CrossRef] 
15. Wang, C.; Zinkevich, M.; Aldinger, F. Phase diagrams and thermodynamics of rare-earth-doped zirconia ceramics. Pure Appl. Chem. 2007, 79. [CrossRef]

16. Chen, M.; Hallstedt, B.; Gauckler, L.J. Thermodynamic modeling of the $\mathrm{ZrO}_{2}-\mathrm{YO}_{1.5}$ system. Solid State Ion. 2004, 170, 255-274. [CrossRef]

17. Tsukuma, K.; Ueda, K.; Shimada, M. Strength and Fracture Toughness of Isostatically Hot-Pressed Composites of $\mathrm{Al}_{2} \mathrm{O}_{3}$ and $\mathrm{Y}_{2} \mathrm{O}_{3}$-Partially-Stabilized $\mathrm{ZrO}_{2}$. J. Am. Ceram. Soc. 1985, 68, C4-C5. [CrossRef]

18. Pȩdzich, Z.; Haberko, K.; Piekarczyk, J.; Faryna, M.; Lityńska, L. Zirconia matrix-tungsten carbide particulate composites manufactured by hot-pressing technique. Mater. Lett. 1998, 36, 70-75. [CrossRef]

19. Jiang, D.; van der Biest, O.; Vleugels, J. $\mathrm{ZrO}_{2}-\mathrm{WC}$ nanocomposites with superior properties. J. Eur. Ceram. Soc. 2007, 27, 1247-1251. [CrossRef]

20. Huang, S.G.; Vanmeensel, K.; van der Biest, O.; Vleugels, J. Development of $\mathrm{ZrO}_{2}-\mathrm{WC}$ composites by pulsed electric current sintering. J. Eur. Ceram. Soc. 2007, 27, 3269-3275. [CrossRef]

21. Salehi, S.; van der Biest, O.; Vleugels, J. $\mathrm{Y}_{2} \mathrm{O}_{3}$ and $\mathrm{Nd}_{2} \mathrm{O}_{3}$ co-stabilized $\mathrm{ZrO}_{2}-\mathrm{WC}$ composites. J. Mater. Sci. 2008, 43, 5784-5789. [CrossRef]

22. Lazarenko, B.R.; Lazarenko, N.I. Elektrische Erosion von Metallen; Cosenergoidat: Moscow, Russia, 1944.

23. Zolotych, B.N.; Proffen, G. Physikalische Grundlagen der Elektrofunkenbearbeitung von Metallen; VEB Technik: Berlin, Germany, 1955.

24. Bonny, K.; de Baets, P.; Vleugels, J.; van der Biest, O.; Lauwers, B.; Liu, W. EDM machinability and dry sliding friction of WC-Co cemented carbides. IJMR 2009, 4, 375-394. [CrossRef]

25. König, W.; Dauw, D.F.; Levy, G.; Panten, U. EDM-Future Steps towards the Machining of Ceramics. CIRP Ann. Manuf. Technol. 1988, 37, 623-631. [CrossRef]

26. Schmitt-Radloff, U.; Gommeringer, A.; Assmuth, P.; Kern, F.; Klocke, F.; Holsten, M.; Schneider, S. Effects of Composition on Mechanical and ED-machining Characteristics of Zirconia toughened Alumina-Titanium Carbide (ZTA-TiC) Composite Ceramics. Procedia CIRP 2018, 68, 17-21. [CrossRef]

27. Schmitt-Radloff, U.; Kern, F.; Gadow, R. Wire EDM of ZTA-NbC Dispersion Ceramics-The Influence of ED Machining on Mechanical Properties. Procedia CIRP 2018, 68, 91-95. [CrossRef]

28. Gommeringer, A.; Schmitt-Radloff, U.; Ninz, P.; Kern, F.; Klocke, F.; Schneider, S.; Holsten, M.; Klink, A. ED-machinable Ceramics with Oxide Matrix: Influence of Particle Size and Volume Fraction of the Electrical Conductive Phase on the Mechanical and Electrical Properties and the EDM Characteristics. Procedia CIRP 2018, 68, 22-27. [CrossRef]

29. Toraya, H.; Yoshimura, M.; Somiya, S. Calibration Curve for Quantitative Analysis of the Monoclinic-Tetragonal $\mathrm{ZrO}_{2}$ System by X-Ray Diffraction. J. Am. Ceram. Soc. 1984, 67, C119-C121. [CrossRef]

30. Panten, U. Funkenerosive Bearbeitung von Elektrisch Leitfähigen Keramiken. Ph.D. Thesis, RWTH Aachen University, Aachen, Germany, 1990.

31. McMurdie, H.F.; Morris, M.C.; Evans, E.H.; Paretzkin, B.; Wong-NG, W.; Hubbard, C.R. Methods of Producing Standard X-Ray Diffraction Powder Patterns. Powder Diffr. 1986, 1, 40-43. [CrossRef]

32. Nakayama, S.; Maekawa, S.; Sato, T.; Masuda, Y.; Imai, S.; Sakamoto, M. Mechanical properties of ytterbia stabilized zirconia ceramics (Yb-TZP) fabricated from powders prepared by co-precipitation method. Ceram. Int. 2000, 26, 207-211. [CrossRef]

33. McMeeking, R.M.; Evans, A.G. Mechanics of Transformation-Toughening in Brittle Materials. J. Am. Ceram. Soc. 1982, 65, 242-246. [CrossRef]

34. Balberg, I.; Azulay, D.; Toker, D.; Millo, O. Percolation and Tunneling in Composite Materials. Int. J. Mod. Phys. B 2004, 18, 2091-2121. [CrossRef]

35. Swain, M.V. Limitation of Maximum Strength of Zirconia-Toughened Ceramics by Transformation Toughening Increment. J. Am. Ceram. Soc. 1985, 68, C-97. [CrossRef]

36. Kern, F. Mechanical properties and microstructure of 1Y2Nd-TZP/20 vol \% alumina nanocomposites. Ceram. Mater. 2012, 64, 168-171. [CrossRef]

37. Kern, F.; Gadow, R. Alumina toughened zirconia from yttria coated powders. J. Eur. Ceram. Soc. 2012, 32, 3911-3918. [CrossRef]

38. Gregori, G.; Burger, W.; Sergo, V. Piezo-spectroscopic analysis of the residual stresses in zirconia-toughened alumina ceramics: The influence of the tetragonal-to-monoclinic transformation. Mater. Sci. Eng. 1999, A271, 401-406. [CrossRef] 
39. Kern, F.; Kabir, A.; Gadow, R. Mechanical properties and low temperature degradation resistance of alumina-doped 3Y-TZP fabricated from stabilizer coated powders. Ceram. Mater. 2017, 69, 279-285.

40. Danilenko, I.; Konstantinova, T.; Volkova, G.; Burkhovetski, V.; Glazunova, V. The Role of Powder Preparation Method in Enhancing Fracture Toughness of Zirconia Ceramics with Low Alumina Amount. J. Ceram. Sci. Technol. 2015, 6, 191-200.

() (1)

(C) 2018 by the authors. Licensee MDPI, Basel, Switzerland. This article is an open access article distributed under the terms and conditions of the Creative Commons Attribution (CC BY) license (http://creativecommons.org/licenses/by/4.0/). 